\title{
The Influence of Nutritional Status on Gross and Fine Motor Skills Development in Early Childhood
}

\author{
Zulkarnaen $^{1}$ \\ ${ }^{1}$ Department of Early Childhood Education, Universitas Muhammadiyah Surakarta, Central Java, Indonesia \\ Correspondence: Zulkarnaen, Department of Early Childhood Education, Universitas Muhammadiyah Surakarta, \\ Jl. A. Yani Tromol Pos 1 Pabelan Kartasura, Central Java-57162, Indonesia. E-mail: zul193@ums.ac.id
}

Received: April 1, 2019

doi:10.5539/ass.v15n5p75
Accepted: April 15, $2019 \quad$ Online Published: April 30, 2019

URL: https://doi.org/10.5539/ass.v15n5p75

\begin{abstract}
This study examines the effect of nutritional status on the gross and fine motor skills development in early childhood. The data were selected randomly using simple random sampling at the Posyandu in East Praya sub-district, Central Lombok, West Nusa Tenggara, Indonesia. The samples were collected 127 children aged 24 to 36 months and their parents as respondents. The regression results showed that nutritional status had positive and significant effect on gross and fine motor skills development of children (adjusted $\mathrm{R}^{2} 41.8 \%$ ). The relationship nutritional status with gross and fine motor skills has the correlation value, 0.650 and moderate relationship level. Increasing the nutritional status greatly helps develop gross and fine motor skills development in children during their golden age.
\end{abstract}

Keywords: early childhood, nutritional status, gross and fine motor skills development

\section{Introduction}

The early childhood development process is unique because children's growth and development coincides with the golden age. The golden age is the most appropriate time to provide strong provisions for children, such as the developing physical basics, language, social-emotional abilities, self-concept, moral arts, and religious values. Efforts to develop all potential early childhood must begin as early as possible, so that children's growth and development optimally achieved. Although children can acquire elementary motor skills through maturation processes, mature forms of skills can only be achieved in developmental friendly environment that provides encouragement, opportunities for specific practice of skills, as well as challenging natural environment, which inspires and aims at integrating skills into different contexts (Sajedi et al., 2016).

Factors that can influence child growth include genetic potential, psychosocial stimuli, nutrition, and a safe and clean physical environment (Black et al., 2017). Factors that influence development psychomotor are (1) Genetic nature (2) Mother prenatal condition, Undernutrition is significant health issue among women of reproductive age (Dalky, Qandil, \& Alqwasmi, 2018) (3) Environmental conditions (4) Health and Nutrition (5) Intelligence quotient (6) The presence of stimulation, encouragement and opportunity (7) Parenting (Democratic, permissive, authoritarian) (8) Physical Disability. Nutritional deficits during this period may cause long-term impairment in child growth and intellectual performance (Prado \& Dewey, 1992). Moreover, factors that can affect child growth include heredity, environment, culture, economy, education, social, climate/weather, and nutrition. Poor stimulation levels in the home, chronic under-nutrition (stunting), iron and iodine deficiencies are key risk factors (Grantham-mcgregor et al., 2013). Psychosocial stimulation and nutritional status had a positive and significant effect on cognitive preschool child development (Warsito et al., 2012).

The main principles of motor development are maturing, sequence, motivation, experience, and practice. The results of Tsapakidou et al., (2014) research showed that suitable, good formed movement programs can develop children's fundamental movement skills. Physical development in children was characterized by the development of gross and fine motor skills. Children can reach the optimal development stage of gross and fine motor skills if they get the right stimulation. The fundamental movement skills influence the confidence and skills needed for active lifestyles later in life. The child development constructs are complex, encompassing cognitive, motor skills and social-emotional domains (Walker et al., 2007). Study on the motor development may provide information regarding the role of nutritional in motor development. The contribution of these factor on motor development may also be assessed from such study. Therefore, the purpose of this study was to investigate 
the effect of nutritional status on gross and fine motor skills development in early childhood.

\section{Literature Review}

\subsection{Gross and Fine Motor Skills Development}

Ability is usually thought to be relatively characteristics or trait. These traits are usually thought of as being either genetically determined or developed through the relatively automatics process in growth and maturation, and they are not easily modifiable by practice or experience, of course, can easily modify by practice or experience Thus, abilities are underlying capabilities that support certain skill (Emmett et al., 2018). Learning motor skills prioritizes the muscle movements, veins, and joints in the body, but help is needed through sensory devices and cognitive processing that involves knowledge and understanding. Because of this complexity, learning motor skills in a psychologist is called perceptual-motor skill or psychomotor skill. Whereas, fine motor skill refers to the movement mainly relying on small muscle and small muscle groups in body parts like hand and fingers, and the ability that can complete a specific task by cooperating with various psychological activities such as sensory perception and attention (Wei, 2017).

The theory of General Motor Ability (GMA) capability was inferred from the performance of movement skills or tasks (locomotor, object control, and body management skills), and strengthened by movement skill foundations (such as flexibility, balance, reaction time, strength, muscle power, etc.) (Hands et al., 2018). This model reminds us that we must consider individual factors, environmental factors, and task factors understand motor development. The progressive acquisition of skills concerns both mental and motor activities are defined as psychomotor development (José et al., 2015). Infant psychomotor development seeks to provide children with several necessary skills to ensure good school performance (Fisher et al., 2005).

\subsection{Nutritional Status}

Nutrition is substances in food that the body needs to function properly (Dunaway \& Richardson, 2004). Adequate nutrition is essential for growth, health, and development of children (Bartolo, 2014). The three basic sources the body uses to provide calories are carbohydrates, proteins and fats and also vitamins and minerals. Benefits from good nutrition including Improved Growth, Better Breathing, Preventing Illness, Improved Motor Function and Better Quality of Life (Families of SMA, 2011). Poor nutrition (substandard diet quantity and quality resulting in under or overnutrition) and the lack of early learning opportunities contribute to the loss of developmental potential and life-long health and economic disparities among millions of children aged $<5$ years (Hurley et al., 2016).

Nutritional status is a measurement of a person's body condition that can be seen from the food consumption and the use of nutrients in the body (Putu et al., 2018). while according to Notes, (2007) Nutritional status is the physiological state of an individual, which results from the relationship between nutrient intake and requirements and from the body's ability to digest, absorb and use these nutrients. The term malnutrition indicates a bad nutritional status. Malnutrition refers to all deviations from adequate nutrition, including undernutrition, overnutrition and specific deficiencies (excesses) of essential nutrients such as vitamins and minerals. Malnutrition arises either from deficiencies or excesses of specific nutrients or from undiversified diets (wrong kinds or proportions of foods). Malnutrition may arise from imbalance, excesses or deficiency of specific nutrients, for example, iodine, vitamin $\mathrm{C}$, iron and vitamin $\mathrm{A}$.

Child growth is internationally recognized as an important indicator of nutritional status and health in populations(WHO, 2010). These indicators are used to measure nutritional imbalance resulting in undernutrition (assessed from underweight, wasting and stunting) and overweight. Assessment of nutritional status is used to determine the state of the nutritional status of children. Nutritional status based on anthropometric standards issued by the Indonesian health ministry. The anthropometric standard refers to the standard World Health Organization (WHO).

Based on the description above, it can be concluded that Nutritional status is the body State due to the food consumption or a successful measure in the fulfillment of nutrition; the balance between the amount intake nutrients and the amount needed (required) by the body for a biological variety functions such as physical growth, development, activity or productivity, health care and others. Nutritional status was divided into two, namely: normal nutritional status and malnutrition. Nutritional status based on body mass index indicators includes Obesity, Fat, Normal, Thin and Very Thin.

\section{Framework}

Motor functioning is a common domain within measures that assess general developmental functioning (Matheis \& Estabillo, 2018). According to Bakhtiar, (2014) Fundamental motor skills are the basic pattern of movements 
to support more complex movement in sports and daily activities. Moreover, experiencing many gross motor skill practices would allow the maturation and development in children's movement system biologically, including large and small muscles, nervous and circulation system. There are three processes involved in learning psychomotor skills, namely, basic learning stage, concentration, and specialization. Furthermore, an individual's ability to perform a movement task can be differentiated by the age difference, purpose and motivation, movement experience, ability, coordination, and training frequency (Aziz, 2017).

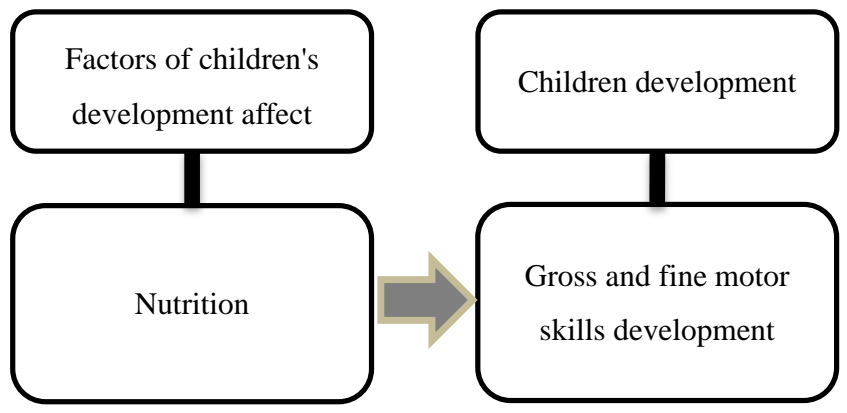

Figure 1. Research Framework

Call Levinson and Jonsson suggest nutritional status affects the gross motor children development. Contemporary GMA models based on Newell's Theory of Constraints (1986) show nutrition is the supporting factors in basic movements such as gross motoric. Remember that factors influencing a child's movement skills according to Lincolnshire Community Health Services NHS Trust, include the child's general development, level of experience and practice, vision and hearing, understanding, attention and listening skills, any genetic or medical issues or conditions. Toddlers, nutritional status is a condition the appearance, physical health produced from the consuming food process and body absorption food nutrients. A child with good nutritional status will have a healthy and strong body to be able to carry out activities that support good gross motor development. Conversely, undernutrition will easily get sick and will have a weak body so they cannot do their activities well. This study framework based on the theory shown in Figure 1.

Gross motor development is the most important factors in individual development as a whole. The physical skills need by children for activities and sports can be learned and trained in the early development stages. Through motor development, children can entertain themselves by gaining pleasure. Like being able to play doll skills, throwing and catching balls or playing games, children can move from helpless conditions in the first months of life, children can move from one place to another and can do it for themselves. This condition can support children's confidence and can adapt themselves to the environment.

\section{Methods}

The data were selected randomly using simple random sampling at the Posyandu in East Praya sub-district, Central Lombok, West Nusa Tenggara, Indonesia. Posyandu is a Community Resource Health Effort carried out by, from and with the community, to empower and provide facilities to the community to obtain health services for mothers, infants, and toddlers. The data for this study were collected in August and September 2017. The sample was collected 127 children and their parents as the respondents. The research subjects were children aged 24 to 36 months and the following inclusion criteria: (1) children aged 24 to 36 months still had mothers, (2) lived with their mother, (3), not twins, (4) not congenital defects, and (5) lived in the sub-district of East Praya.

Child nutritional status data were assessed anthropometrically for body weight and height z-score is then categorized according to anthropometry books. Gross and fine motoric development consist of 40 test items. The development test consists of gross and fine motor skills. The criteria for gross and fine motor development are very slow if the index score is less than 70 , slow if the index score is $70-84$, normal if the index score is $85-114$ and fast if the index score is more than 114.

\subsection{Nutritional Status Assessment}

Assessment of nutritional status can be used to determine the state of children's nutritional status. In this study, which was used to determine nutritional status is an anthropometric assessment of nutritional status which is the basis of the assessment of nutritional status. The anthropometric index is the ratio of measurement to one or more measurements that are related to age. Some anthropometric indices are body weight for age, height to age, body weight to height, upper-arm circumference for age, Body Mass Index (BMI), thick fat under the skin for age, waist and hip circumference. 
The Body Mass Index (BMI) is also an indicator of nutritional status often used due to the ease of its application, the existence of reference patterns that allow comparisons between populations, it not being invasive and also not an expensive process (Helena et al., 2015). The formula for determining the BMI value is Formula BMI = body weight $(\mathrm{BW}) / \mathrm{HEIGHT}^{2}\left(\mathrm{~m}^{2}\right)$. Assessment of nutritional status based on body weight to age indicators, the results of anthropometric measurements are converted into standard deviation z-score (z-score) using program entries nutrition.

\subsection{Gross and Fine Motor Skills Assessment}

Gross motor skills are scores obtained from measurements in the form of questionnaires obtained using a test of action with three choices of answers that are less given a score of 1, simply given a score of 2 and best scores 3 . This score describes motor skills as a rude child who includes endurance, speed, flexibility, agility, balance, and strength. The measurement of gross motor skills as outlined in the questionnaire is based on the Standard of Early Childhood Education.

\subsection{Data Analysis}

Data analysis in this study is a descriptive analysis, correlation test, and simple regression analysis. Descriptive analysis to calculate the number and percentage of categories, minimum values, maximum values, average values, and standard deviations of each research variable. Pearson correlation test to analyze the relationship between the variables of the study. Then the simple regression analysis was used to analyze the influence of the nutritional status on gross and fine motor skills development.

\section{Results}

The largest percentage $87.40 \%$, mean 94.37 and Standard Deviation 8.85 (Table 1) of children were in the Normal Gross and Fine Motor Development category. The nutritional status of children showed that $96.06 \%$ Normal Weight of children, mean 0.36 and Standard Deviation of 1.03.

Table 1. Descriptive Statistics

\begin{tabular}{cccccc}
\hline & N & Minimum & Maximum & Mean & Std. Deviation \\
\hline Nutritional Status & 127 & 30 & 44 & 38.22 & 2.98 \\
Gross and Fine Motor Skills & 127 & 68 & 115 & 94.37 & 8.85 \\
\hline
\end{tabular}

Categories gross and fine motor development, namely fast, normal, slow, and very slow. Normal categories showed the largest percentage $(87.40 \%)$ and the fast categories $(0.79 \%)$. Nutritional status has four categories and normal weight categories showed the largest percentage (96.06\%) and severe underweight categories (0\%). Categories and distribution of the respondents and children at Table 2.

Table 2. The Respondents Categories and Distribution $(\mathrm{N}=127)$

\begin{tabular}{ccc}
\hline Variable Categories & $\mathrm{N}$ & $\%$ \\
\hline Gross and Fine Motor Development & & $0.79 \%$ \\
Fast (<114 & 1 & $87.40 \%$ \\
Normal (85-114) & 111 & $10.24 \%$ \\
Slow (70-84) & 13 & $1.57 \%$ \\
Very Slow (>70) & 2 & $0.79 \%$ \\
Nutritional Status & & $96.06 \%$ \\
Over Weight (> 2 SD) & 1 & $3.15 \%$ \\
Normal Weight (-2 SD To 2 SD) & 122 & $0.00 \%$ \\
Under Weight (-3 SD To <-2 SD) & 4 & 0 \\
Severe Under Weight (<-3 SD) & &
\end{tabular}

Based on the statistical test result found that nutritional status with gross and fine motor skills has the correlation value, $0.650 ; 42.3 \%$ (Table 3 ) and relationship level is moderate.

Table 3. The Correlation between Variables, Determinant Coefficient and Relationship Level

\begin{tabular}{cccc}
\hline Correlation & $\mathrm{R}^{2}$ & Determinant Coefficient & Relationship Level \\
\hline Correlation Nutritional Status With Gross And Fine Motor Skills & 0.650 & $42.3 \%$ & Moderate \\
\hline & $* * . \rho<0.001$ \\
\hline
\end{tabular}


The results of stepwise regression tests showed that nutritional status $(\rho<0.001)$ had a positive and significant effect on gross and fine motor skills children development (adjusted $\mathrm{R}^{2}, 0.418, \rho<0.001$ ) table 4 . This result indicated that $41.8 \%$ of a child's gross and fine motor skills can be explained by nutritional status variables. Thus, the increasingly good nutritional status will further improve gross and fine motor skills children development.

Table 4. Regression Analysis

The Dependent Variable: Gross and Fine Motor Skills

\begin{tabular}{|c|c|c|c|c|c|}
\hline \multirow{2}{*}{ Model } & \multicolumn{2}{|c|}{ Unstandardized Coefficients } & \multirow{2}{*}{$\frac{\text { Standardized Coefficients }}{\text { Beta }}$} & \multirow{2}{*}{$\mathrm{t}$} & \multirow{2}{*}{ Sig. } \\
\hline & $\mathrm{B}$ & Std. Error & & & \\
\hline \multirow[t]{2}{*}{ Nutritional Status } & 5.591 & 0.585 & 0.650 & 9.558 & 0.000 \\
\hline & & ed R2, 0.418 & & & \\
\hline
\end{tabular}

\section{Discussion}

The results of this study indicate the significant effect nutritional status on gross and fine motor skills in early childhood. Moreover, there was positive relationship between nutritional status on gross and fine motor skills in early childhood. This means good nutritional status will further improve gross and fine motor skills in children. Physical activity is important for numerous aspects of children's health and development (Janssen \& Leblanc, 2010). Physical activity in the early childhood years promotes the gross motor development and fundamental movement skills, which are the building blocks for the confidence and skills needed for active lifestyles later in life (Fisher et al., 2005). Furthermore, children who have high energy supplementary foods, combined with micronutrients run faster and more active.

Similar observations have been reported by other research workers in children showed relationship between nutritional status with gross motor skills such as research by Ati et al., (2013) in their study found that there was significant relationship between nutritional status and gross motoric children development. In addition, Grantham-McGregor et al., (1999) their research concluded motoric is closely related to nutritional status, in body length to age terms and body weight according to age. The same was obtained from the study Putri et al., (2015) there was significant relationship between the relationship between nutritional status and gross motor development in children aged 1-3 years. Indriyani \& Permatasari, (2014) also found a relationship between nutritional status and the development of children aged 1-5 years.

The significant association between anthropometric status and psychomotor functioning and also anthropometric status (Abubakar et al., 2008). Both acute and chronic malnutrition measures significantly affect the baseline developmental status as well as the rate of improvement in cognitive determinant and psychomotor development scores (Park et al., 2011). Children with obesity displayed lower gross motor skill levels compared with peers of healthy weight and the largest differences were seen in locomotor and balance skills (Roberts et al., 2012).

There was significant and positive relationship between iron intake and both total and non-verbal IQ (Arija et al., 2006). The development of children may be influenced by their nutritional status, and obesity may pose risks in gross motor performance terms (Onofre et al., 2017). Children who are overweight or obese may have perceptual-motor coordination issues that influence not an only gross motor, but fine motor skills as well (Hondt et al., 2008). Children with obesity displayed lower gross motor skill levels compared with peers of healthy weight. Larger differences were seen in locomotor and balance skills (Roberts et al., 2012). Motor skills are adversely associated with childhood obesity only for skills most directly related to body weight (Castetbon \& Andreyeva, 2012).

Childhood obesity and gross motor skill development area, both intrinsic result (child) and extrinsic (environmental) factors namely family income. Nutritional status is closely associated with family income. Several studies have shown a link between nutrition and family income (environmental), including research by (Lyatuu et al., 2016) Micronutrient deficiency in Tanzania is a significant public health problem, with vitamin A and nutritional deficiency in children due to a family income still below the national average that affects $34 \%$ of children aged 6 to 59 months since 2007. Similarly, conducted by (Barnhill, 2013) that the relationship between the nutritional level of children with the level of family income. (Safron et al., 2011), their study also found a significant relationship between family income, nutritional status, physical and environmental characteristics. Ghosh et al., (2013) found that nutritional status and socio-economic status of surveyed boys appear to be significant predictors for their fine and gross motor development. Additionally, Santal children with lower 
socioeconomic status and poor nutritional status have lower motor proficiency compared with Santal children with comparatively higher socioeconomic status and nutritional status (Dutta et al., 2010).

Based on the results and opinions, these studies were concluded nutritional status significantly associated with gross and fine motor skills children development. Achieving good nutritional status must be supported by food consumption contain enough nutrients and safe for consumption. Children with good and healthy nutritional status are more likely to have better motor skills and have a higher life expectancy and productive time. It is reasonable the food and nutrition objectives policy in Indonesia, improve the population nutritional quality, especially nutrition vulnerable groups such as children under three years old (toddlers). Therefore, attention meeting the nutritional and health adequacy increasingly important.

\section{Conclusions}

The present findings confirm previous research on the influence nutritional status has a significant effect on gross and fine motor skills in children. Attention to gross and fine motor skills children development must be considered carefully. These factors must be considered carefully so that children's development related to gross and fine motor skills can be achieved optimally. Motor skills are a significant component of adaptive behaviors because the coordination of both fine and gross motor skills is necessary for the development of various self-care and community living skills (Matheis \& Estabillo, 2018).

Toddlers, nutritional status are a condition shown by the appearance of physical health produced from the process of consuming food, absorption and food nutrient use by the body. A child with good nutritional status will have a healthy and strong body to be able to carry out activities that support good gross and fine motor skills development. Conversely, children who are undernutrition will easily get sick and will have a weak body so they cannot do their activities well.

\section{Limitations}

Efforts to improve gross and fine motor skills can be done by providing regular and continuous training according to the child's age stage. If improved nutrient intake can be considered the gross and fine motor skills will certainly increase, so that the healthy generation, intelligent and qualified generation can be achieved. Government and community attention given to the family directly will have a positive impact on family life, especially on nutritional status.

Certainly, the improvement of living standards and family health status can be done by the government establishes a policy the societal interests, especially families with low economic status. Schools should provide facilities that can develop children's abrasive motor skills. School and government should provide nutrition-related assistance, such as regular nutrition for children on a regular basis.

Governments as policymakers play an important role in improving human resources quality. Further research on motor development can be associated with other factors such as children's cognitive development, socioeconomic status and home environment (parenting).

\section{Acknowledgments}

The authors gratefully acknowledge all the children and parents who gave up their time to participate in this study and for all assistance received from the community health staff center in the East Praya sub-district. We also thank you to the head of the East Praya sub-district.

\section{References}

Abubakar, A., Vijver, F. Van De, Baar, A. Van, Mbonani, L., Kalu, R., Newton, C., \& Holding, P. (2008). Socioeconomic status, anthropometric status, and psychomotor development of Kenyan children from resource-limited settings: A path-analytic study, 613-621. https://doi.org/10.1016/j.earlhumdev.2008.02.003

Arija, V., Esparó, G., Fernández-Ballart, J., Murphy, M. M., Biarnés, E., \& Canals, J. (2006). Nutritional status and performance in test of verbal and non-verbal intelligence in 6 year old children. Intelligence, 34(2), 141-149. https://doi.org/10.1016/j.intell.2005.09.001

Ati, C. A., Alfiyanti, D., \& Solekhan, A. (2013). Hubungan Antara Status Gizi Dengan Perkembangan Motorik Kasar Anak Balita Di RSUD Tugurejo Semarang Tahun 2013. Jurnal Ilmu Keperawatan Dan Kebidanan, 33(4), 1-8.

Aziz, I. (2017). Evaluating Learning Outcomes of Sports Skills through Observation. Asian Social Science, 10(5), 130-135. https://doi.org/10.5539/ass.v10n5p130

Bakhtiar, S. (2014). Fundamental Motor Skill among 6-Year-Old Children in Padang, West Sumatera, Indonesia. 
Asian Social Science, 10(5), 155-158. https://doi.org/10.5539/ass.v10n5p155

Barnhill, A. (2013). Nutritionism, Commercialization and Food, 1(3), 223-225. https://doi.org/10.15171/ijhpm.2013.41

Bartolo, M. (2014). Nutrition in childhood, 3(1).

Black, M. M., Walker, S. P., Fernald, L. C. H., Andersen, C. T., DiGirolamo, A. M., Lu, C., ... Grantham-McGregor, S. (2017). Early childhood development coming of age: science through the life course. The Lancet, 389(10064), 77-90. https://doi.org/10.1016/S0140-6736(16)31389-7

Castetbon, K., \& Andreyeva, T. (2012). Obesity and motor skills among 4 to 6-year-old children in the united states: Nationally- representative surveys.

Dalky, H. F., Qandil, A., \& Alqwasmi, A. A. (2018). Factors Associated With Undernutrition Among Pregnant and Lactating Syrian Refugee Women in Jordan. Global Journal of Health Science, 10(4). https://doi.org/10.5539/gjhs.v10n4p58

Dunaway, I., \& Richardson, S. J. (2004). An Introduction to Nutrition (December).

Dutta, S., Wrotniak, B. H., \& Ghosh, T. (2010). Early Human Development Nutritional and socioeconomic factors in motor development of Santal children of the Purulia district, India. Early Human Development, 86(12), 779-784. https://doi.org/10.1016/j.earlhumdev.2010.08.029

Emmett, S. D., Schmitz, J., Karna, S. L., Khatry, S. K., Wu, L., Leclerq, S. C., \& Pillion, J. (2018). Early childhood undernutrition increases risk of hearing loss in young adulthood in rural Nepal, (March), 268-277. https://doi.org/10.1093/ajcn/nqx022

Fisher, A., Reilly, J. J., Kelly, L. A., Montgomery, C., Williamson, A., Paton, J. Y., \& Grant, S. (2005). Fundamental Movement Skills and Habitual Physical Activity in Young Children. Journal of the American College of Sports Medicine, 37(4)(6 d), 684-688. https://doi.org/10.1249/01.MSS.0000159138.48107.7D

Ghosh, S., Chowdhury, S. D., \& Chandra, A. M. (2013). A study on the influence of occupation on development of motor activities in children, 3843. https://doi.org/10.1080/02673843.2011.651150

Grantham-McGregor, S., Fernald, L., \& Sethuraman, K. (1999). Effects of health and nutrition on cognitive and behavioural development in children in the first three years of life. Part 2: Infections and micronutrient deficiencies: Iodine, iron, zinc. Food and Nutrition Bulletin, 20(1), 76-99. Retrieved from http://www.ingentaconnect.com/content/nsinf/fnb/1999/00000020/00000001/art00007

Hands, B., McIntyre, F., \& Parker, H. (2018). The General Motor Ability Hypothesis: An Old Idea Revisited. Perceptual and Motor Skills, 125(2), 213-233. https://doi.org/10.1177/0031512517751750

Helena, M., Oehlschlaeger, K., Pastore, C. A., Cavalli, A. S., \& Gonzalez, M. C. (2015). Original / Ancianos Nutritional status, muscle mass and strength of elderly in Southern Brazil. Nutr Hosp, 31(1), 363-370. https://doi.org/10.3305/nh.2015.31.1.7264

Hondt, E. D., Deforche, B., Bourdeaudhuij, I. De, \& Lenoir, M. (2008). Neuroscience Letters Childhood obesity affects fine motor skill performance under different postural constraints, 440, 72-75. https://doi.org/10.1016/j.neulet.2008.05.056

Hurley, K. M., Yousafzai, A. K., \& Lopez-boo, F. (2016). Early Child Development and Nutrition : A Review of the Bene fi ts and Challenges of Implementing Integrated Interventions 1-4. American Society for Nutrition, 357-363. https://doi.org/10.3945/an.115.010363.by

Indriyani, R., \& Permatasari, D. (2014). Hubungan Status Gizi Dengan Perkembangan Anak Usia Toodler (1-3 Tahun) Di Desa Aeng Tongtong Kecamatan Saronggi Kabupaten Sumenep TahuN 2014. Jurnal Kesehatan "Wiraraja Medika", 99-107.

Janssen, I., \& Leblanc, A. G. (2010). Systematic review of the health benefits of physical activity and fitness in school-aged children and youth.

José, H., Costa, T., Abelairas-gomez, C., Arufe-giráldez, V., Pazos-couto, J. M., \& Barcala-furelos, R. (2015). Influence of a physical education plan on psychomotor development profiles of preschool children. Journal Of Human Sport \& ExercisE, 10(1), 126-140. https://doi.org/10.14198/jhse.2015.101.11

Lincolnshire Community Health Services NHS Trust. (n. d.). 1st Move A gross and fine motor skills resource. Retrieved from www.lincolnshirecommunityhealthservices.nhs.uk

Lyatuu, M. B., Mkumbwa, T., Stevenson, R., Isidro, M., Modaha, F., Katcher, H., \& Dhillon, C. N. (2016). 
Planning and Budgeting for Nutrition Programs in Tanzania: Lessons Learned From the National Vitamin A Supplementation Program. International Journal of Health Policy and Management, 5(10), 583-588. https://doi.org/10.15171/ijhpm.2016.46

Matheis, M., \& Estabillo, J. A. (2018). Assessment of Fine and Gross Motor Skills in Children. https://doi.org/10.1007/978-3-319-93542-3

Notes, L. (2007). Nutritional Status Assessment and Analysis. Nutritional Status Assessment and Analysis Nutritional.

Onofre, P. S. D. C., Nosse, N. C. P., Gesteira, E. C. R., Costa, M. A., Belinelo, R. G. S., \& de Oliveira, P. P. (2017). Assessment of nutritional status in comparison to neuropsychomotor development in children : a descriptive study. Brazilian Journal of Nursing, (January). https://doi.org/10.17665/1676-4285.20155120

Park, H., Bothe, D., Holsinger, E., Kirchner, H. L., Olness, K., \& Mandalakas, A. (2011). The impact of nutritional status and longitudinal recovery of motor and cognitive milestones in internationally adopted children. International Journal of Environmental Research and Public Health, 8(1), 105-116. https://doi.org/10.3390/ijerph8010105

Prado, E. L., \& Dewey, K. G. (1992). Nutrition and brain development in early life, 72(4), $267-284$. https://doi.org/10.1111/nure.12102

Putri, T. S. S., Priyanto, \& Muflihah, I. S. (2015). Hubungan Status Gizi Dengan Perkembangan Motorik Kasar Pada Anak Usia 1-3 Tahun Di Kelurahan Bandarjo Kabupaten Semarang Tahun 2015, 1-13.

Putu, P., Sugiani, S., \& Suarni, N. N. (2018). Description of nutritional status and the incidence of stunting children in early childhood education programs in Bali-Indonesia. Bali Medical Journal (Bali Med J), 7(3), 723-726. https://doi.org/10.15562/bmj.v7i3.1219

Roberts, D., Veneri, D., Decker, R., \& Gannotti, M. (2012). Weight status and gross motor skill in kindergarten children. Pediatric Physical Therapy, 24(4), 353-360. https://doi.org/10.1097/PEP.0b013e3182680f19

Safron, M., Cislak, A., Gaspar, T., \& Luszczynska, A. (2011). Effects of school-based interventions targeting obesity-related behaviors and body weight change: A systematic umbrella review. Behavioral Medicine, 37(1), 15-25. https://doi.org/10.1080/08964289.2010.543194

Sajedi, F., Doulabi, M., Vameghi, R., \& Baghban, A. A. (2016). Development of Children in Iran : A Systematic Review and. Global Journal of Health Science, 8(8), 145-161. https://doi.org/10.5539/gjhs.v8n8p145

SMA, F. (2011). Fostering Health and Growth for Spinal Muscular Atrophy. Retrieved from www.curesma.org

Tsapakidou, A., Stefanidou, S., \& Tsompanaki, E. (2014). Locomotor Development of Children Aged 3.5 to 5 Years in Nursery Schools in Greece. Review of European Studies, 6(2), 1-6. https://doi.org/10.5539/res.v6n2p1

Walker, S. P., Wachs, T. D., Gardner, J. M., Lozoff, B., Wasserman, G. A., Pollitt, E., \& Carter, J. A. (2007). Child development in developing countries 2 Child development: Risk factors for adverse outcomes in developing countries, 145-157.

Warsito, O., Khomsan, A., Hernawati, N., \& Anwar, F. (2012). Relationship between nutritional status, psychosocial stimulation, and cognitive development in preschool children in Indonesia. Nutrition Research and Practice, 6(5), 451-457. https://doi.org/10.4162/nrp.2012.6.5.451

Wei, X. (2017). Research on Status quo of Fine Motor Skill of Children Aged 3 to 6: Case Analysis of Kindergartens in Nanchong, Sichuan. Asian Social Science, 12(4), 125-130. https://doi.org/10.5539/ass.v12n4p125

WHO. (2010). Nutrition Landscape Information System (NLIS) Country Profile indiCators: Interpretation Guide.

\section{Copyrights}

Copyright for this article is retained by the author(s), with first publication rights granted to the journal.

This is an open-access article distributed under the terms and conditions of the Creative Commons Attribution license (http://creativecommons.org/licenses/by/4.0/). 